\title{
EL PATRIMONIO SOCIO-CULTURAL DE LOS JUEGOS OLÍMPICOS DE ATENAS 2004
}

\author{
Ewa Malchrowicz-Mośko \\ ewa.malchrowicz@poczta.onet.pl \\ Academia de Educación Física de Poznan, Polonia \\ Adam Omorczyk \\ adam.omorczyk@gmail.com \\ Universidad de Opole, Polonia \\ María Teresa Calle Molina \\ mariat.calle@uam.es \\ Universidad Autónoma de Madrid, España \\ Fecha de recepción: Noviembre 2015 \\ Fecha de aceptación: Marzo 2016 \\ http://dx.doi.org/10.15366/citius2016.9.1.005
}

\section{Resumen:}

Con el objetivo de presentar los ejemplos positivos y negativos del patrimonio de los Juegos Olímpicos que tuvieron lugar en Atenas en el 2004, se realizó un análisis exhaustivo de autores de referencia en el ámbito, de los informes oficiales de los Juegos y una observación mediante una visita a Atenas en marzo de 2013 y a Olimpia en 2015. A pesar de la complejidad que supone el análisis del patrimonio de un evento deportivo como son los Juegos Olímpicos y la determinación de sus efectos tiempo después, se ha podido apreciar que en el caso de Atenas 2004 es apreciable. En este caso es manifiesto, a pesar de los gastos financieros que la ciudad sufragó con motivo de la organización del evento, que gran parte del patrimonio material se está deteriorando. Esta investigación supone un estudio sobre el patrimonio material y la conservación en buen estado del mismo que, consideramos, supone el escaparate que muestra la voluntariedad de un país de acoger de nuevo la organización de otra edición de los Juegos Olímpicos.

Palabras claves: Juegos Olímpicos, metamorfosis urbana, patrimonio olímpico. 
Title: THE SOCIO-CULTURAL HERITAGE OF THE OLYMPICS IN ATHENS 2004

\begin{abstract}
:
In order to expose the positive and negative examples of the heritage of the Olympic Games that took place in Athens in 2004, was carried out a comprehensive analysis of reference authors in the field, an analysis of the official reports of the Games and an observation through a visit to Athens in 2013 and to Olympia in 2015. Despite the complexity of the analysis of the heritage of a sporting event such as the Olympics and determining its effect some time later, it has been seen that in the case of Athens 2004 is appreciable. In this case it is manifest, even though the city covered the financial expenses due to the organization of the event, much of the material heritage is deteriorating. This research provides a study of the material heritage and its maintenance, as we consider, that this means the voluntariness of a country to host again organizing another edition of the Olympic Games.
\end{abstract}

Key words: Olympic Games, urban metamorphosis, Olympic heritage.

\title{
1. Atenas 1986-2004
}

Atenas tuvo el honor de organizar los primeros Juegos Olímpicos restaurados de la historia. El evento, en 1896, a pesar de tener problemas de gran calado en cuanto a la organización debido a la inexistencia de otros Juegos de tal magnitud con anterioridad, ${ }^{30}$ tuvo el éxito suficiente para que se sucedieran ediciones posteriores. Como apunta Durántez Corral (2012) "los Juegos de Atenas en conjunto fueron un éxito y trajeron con su frescura innovadora, una llamada de ilusión y de inquietud internacional" (p.71).

En el año 2004, Grecia volvió a disponer de la opción de poder organizar de nuevo este evento deportivo, en esta ocasión, con unas dimensiones aumentadas en todos los niveles con respecto a la anterior ocasión. Tras once candidaturas, las cuales se redujeron a cinco, Atenas fue la elegida frente a Roma tras "una apretada pugna que necesitó cinco vueltas de escrutinio" (Durántez Corral, 2012, p.331), con cuarenta y seis votos frente a cuarenta y uno. La designación de esta candidatura tuvo fecha en 1997, justamente siete años después de que el Comité Olímpico Internacional se decidiera por Atlanta para acoger los Juegos del Centenario, con el pesar del gobierno y del pueblo griego por la historia que guardaba su país ${ }^{31}$. Atenas, por tanto, albergó por segunda vez unos Juegos

\footnotetext{
${ }^{30}$ Durántez Corral, C. (2012). Los Juegos: las olimpiadas en la historia. Madrid: EDAF

${ }^{31}$ Bravo Ducal, J. (2008). Atenas 1896, Atenas 2004. Madrid: Real Federación Española de Atletismo y Comité Olímpico Español.
}

Citius, Altius, Fortius Volumen 9 ne 1 Mayo, 2016. ISHN. 2340-9886.

http://dx.doi.org/10.15366/eitius2016.9.1 
Olímpicos tras su restauración moderna en 1896 y su creación veintiocho siglos atrás. ${ }^{32}$

En aquel momento, ya era una evidencia a nivel mundial el hecho de que política y económicamente el país que acogiera los Juegos debía tener ciertas características que ofrecieran seguridad al evento y a sus participantes. En aquellas circunstancias, Grecia no reunía las condiciones que otros países podían proporcionar, sin embargo, su historia reveló la importancia que en todos los ámbitos aquel país tenía en relación con los Juegos Olímpicos. Indiscutiblemente, las aportaciones históricas del país, fueron el valor que con más peso pudieron aportar para poder volver a organizar unos Juegos Olímpicos.

\section{El patrimonio olímpico}

Aún hoy se constata la aparición del concepto de patrimonio olímpico en los documentos estratégicos del Comité Olímpico Internacional desde los años noventa como una cuestión sociopolítica importante y un campo de investigaciones científicas multidisciplinares. ${ }^{33}$ La discusión sobre el patrimonio de eventos deportivos de tales magnitudes fue el resultado a la pregunta sobre cuáles son los efectos positivos y negativos de su organización, no sólo en el aspecto económico, sino también social, cultural y ecológico. Este tema interesaba no sólo los organizadores de los Juegos, sino también a algunos especialistas del área, ${ }^{34}$ quienes distinguen diversos tipos de patrimonio: social, cultural, ecológico, urbano, deportivo y económico. Patrimonio que puede ser material e inmaterial ${ }^{35}$.

El patrimonio de un evento deportivo son todos aquellos cambios permanentes y de larga duración que la organización de los mismos produce en el país y en la sociedad, en el entorno directo de los habitantes y a nivel internacional. Las experiencias de los países organizadores de grandes eventos deportivos, como por ejemplo los Juegos Olímpicos, son una prueba de que todos estos cambios permanentes y de larga duración tienen un impacto diferente sobre su entorno.

El patrimonio material no es aquel que en exclusiva está destinado a la práctica deportiva, sino el que genera espacios aptos para albergar un evento de estas características. La construcción de carreteras, autopistas o nuevos medios de transporte deben tenerse en cuenta, por ejemplo, para la facilitación de una

\footnotetext{
${ }^{32}$ Durántez Corral, C. (2004). Las olimpiadas modernas. Madrid: Pearson Educación.

${ }^{33}$ Girginov V., (2012). Social legacy of the Olympic Games, Learning Legacies.

${ }^{34}$ Chappelet J.L. (2012). Mega sporting event legacies: a multifaceted concept, Papeles de Europa, pp. 76-86.

35 www.olympic.org/documents/olympism_in_action/legacy/2013_booklet_legacy.pdf.
} 
comunicación que soporte un número de visitantes diferente al de su realidad habitual. El patrimonio inmaterial es también importante y, aunque es difícil su medida, es apreciable. El efecto de atractivo turístico, la popularización del deporte, la promoción de la actividad física o del estilo de vida saludable, así como otros muchos de sus aspectos son aquellos valores añadidos que pueden promover este tipo de eventos y que se deben tener en cuenta. Por ejemplo, el patrimonio social de un gran evento deportivo se define como "el cambio en el sistema de valores de los individuos o sociedades enteras causado por viajes deportivos, el cambio en tipos de comportamiento de turistas y población local, sus estructuras sociales, estilo de vida y el nivel de calidad de vida". ${ }^{36}$ Por ello, es un valor añadido determinar cuáles son los efectos que conforman todas aquellas consecuencias resultantes de la celebración de un evento, sobre todo, para la sociedad local, es decir, los habitantes de la ciudad y región donde el evento ha tenido lugar.

Todos estos aspectos, difíciles de medir y complejos de garantizar, son ámbitos esenciales en las competencias que la organización asume en la planificación y preparación de un evento de estas características. El efecto del patrimonio olímpico puede ser positivo o negativo, por ello es importante medir sus consecuencias. Algunos organizadores sufren pérdidas que no son recuperadas en los ingresos procedentes del sector turístico tras el evento. Es por ello, que este estudio muestra alguno de los efectos positivos y negativos del patrimonio material de los Juegos Olímpicos del 2004 celebrados en Atenas, Grecia, doce años después de su organización.

\section{Patrimonio material de los Juegos Olímpicos de Atenas 2004}

En el momento de presentar su candidatura para poder organizar los Juegos, Atenas ya tenía una parte de las instalaciones que se requerían. El complejo O.A.K.A. o el Estadio de la Paz y la Amistad son un ejemplo, ya que eran instalaciones que habían albergado con anterioridad otros eventos deportivos de carácter internacional. Sin embargo, muchas de estas instalaciones necesitaban reparaciones a nivel general o cierta modernización en las mismas. La esperanza en cuanto a la metamorfosis que podía experimentar la capital griega se apoyaba en aquellas instalaciones que debían construirse y que aún era necesario levantar para albergar unos Juegos Olímpicos.

El dossier que Atenas presentó como propuesta para su candidatura recogía

\footnotetext{
${ }^{36}$ Hall C. (1992). Adventure, Sport and Health Tourism, [w:] B. Weiler, C. Hall (red.), Special Interest Tourism, Bellhaven Londres. pp. 141-158.
}

Citius, Altius, Fortius Volumen 9 ne 1 Mayo, 2016. ISHN. 2340-9886.

http://dx.doi.org/10.15366/eitius2016.9.1 
diversos aspectos, algunos fueron la proposición del aumento de instalaciones y complejos arquitectónicos ya existentes, la planificación de construcción de otras áreas relacionadas o el plan de desarrollo de la red de transporte. Un elemento esencial de aquel documento fueron los cuatro puntos más importantes del plan de ordenación territorial: el plano de la red de circunvalación olímpica de Atenas; el ensache de las dos principales instalaciones deportivas (O.A.K.A. y Faliron) conectadas con la carretera de circunvalación; la reducción de las instalaciones deportivas autónomas y la optimización de uso de las instalaciones deportivas existentes. ${ }^{37}$

Atenas no era un lugar especialmente idóneo para organizar los Juegos desde la perspectiva de la comunicación y ya en 1997 se planteaban cuestiones como la posibilidad de que existiera cierta crisis de comunicación, con los riesgos que el verano griego conllevaba, ${ }^{38}$ si la afluencia de turismo era importante. No obstante, ya existía parte de la infraestructura de comunicación, pues la ciudad ya gozaba de una red de calles y carreteras con pronóstico de que conformaran una red de carreteras principales y secundarias de lo que fue la circunvalación olímpica. Esta circunvalación tenía por objeto comunicar las instalaciones deportivas más importantes de los Juegos y, al mismo tiempo, mejorar la red de trasportes de la ciudad. Por lo que, se modernizó la línea 1 del metro y se construyeron dos líneas más: la línea 2 y 3 , las cuales se pusieron en funcionamiento para el público desde el año 2000. Adicionalmente, se construyó una red de tranvía con tres líneas, de tal manera que comunicaran el centro de Atenas con la costa y, por consiguiente, con gran parte de las instalaciones olímpicas localizadas en sus alrededores. Además, se alargó la línea ferroviaria hasta el nuevo aeropuerto, ${ }^{39}$ que se puso en funcionamiento en 2001 sustituyendo el antiguo aeropuerto de Ellinikon.

Del mismo modo, se procedió a una modernización de autobuses y la red de carreteras urbanas. A pesar de que aquellas infraestructuras no parecieran estar estrechamente relacionadas con la circunstancia deportiva de los Juegos, en realidad, eran un elemento esencial para su buen funcionamiento. Se podía constatar que era necesaria una remodelación de ciertas infraestructuras y, gracias a la organización de los Juegos, las carreteras, circunvalaciones o líneas ferroviarias, de tranvía o metro se beneficiaron de esta oportunidad. Estos elementos además de ser facilitadores antes y durante los Juegos, fueron una adquisición valiosa a largo plazo para la ciudadanía griega y su turismo.

\footnotetext{
37 "Atenas 2004" - Informe Oficial, p. 143.

${ }^{38}$ Miller D. (2012). Historia igrzysk olimpijskich i Międzynarodowego Komitetu Olimpijskiego. Od Aten do Londynu 1984-2012, Dom Wydawniczy REBIS, Poznań/Polska/Polonia. p. 362.

39 "Atenas 2004" - Informe Oficial, p. 171.
}

Citius, Altius, Fortius Volumen 9 ne 1 Mayo, 2016. ISNN. 2340-9886. http://dx.doi.org/10.15366/citius2016.9.1 
En estos Juegos, el eje vertebral del evento deportivo era el Complejo Olímpico de Deportes de Atenas Spyros Louis "Olympic Atheltic Center of Athens 'Spiros Louis'" (O.A.K.A.), ${ }^{40}$ renombrado tras su reconstrucción en honor al maratoniano griego que ganó en la primera edición. Este complejo fue usado anteriormente para organizar varios eventos deportivos de carácter internacional. Incluye un estadio olímpico, un velódromo, instalaciones acuáticas y dieciséis pistas de tenis. A pesar de su uso en otros eventos internacionales, debían ser remodeladas para aquella ocasión y, para ello, se eligió al arquitecto español Santiago Calatrava. Tras quince meses de reconstrucción, la forma y el espacio del complejo eran su característica más notoria. En él estaban previstos los actos de apertura y clausura de los Juegos y diversas competiciones deportivas. El terreno donde antes se ubicaban las canchas se transformó en el Ágora, constituida por unos arcos que la hicieron característica, ya que dejaba espacio para el área de descanso y paseo, con árboles, estanques y fuentes. También en este espacio se construyó el Muro de las Naciones el cual, con doscientos cincuenta metros de largo y gracias a su movilidad arquitectónica, creaba un efecto de ola y sombras.

Dejando de lado las diversas obras arquitectónicas que componían el complejo que albergó estos Juegos, otros elementos imprescindibles dieron la funcionalidad necesaria a las instalaciones, como fueron los elementos de señalización internacional. El ambiente finalmente, estuvo óptimamente organizado para crear un entorno de festejo, diversión e internacionalidad. Tras las dos semanas de duración, estos espacios fueron reconvertidos a otra realidad que les debía dar una nueva funcionalidad.

\section{Patrimonio material en Atenas tras la celebración de los Juegos del 2004}

Tras la revisión documental de los elementos que conforman el patrimonio olímpico, se hizo una visita en marzo del año 2013 a las instalaciones que se construyeron para los Juegos Olímpicos de Atenas 2004. El objetivo era la observación del mantenimiento, funcionalidad y estado de éstas. Además de la observación directa de las mismas y la descripción de las observaciones, se recogieron las muestras gráficas que contrastan las descripciones.

Las zonas de las que se componía el grupo de construcciones arquitectónicas de O.A.K.A. no fueron tapadas con pavimento y, era apreciable, que habían crecido hierbas a su alrededor. Los árboles, dispuestos con un fin estético en los Juegos, estaban secos; las placas de cristal que iluminaban el recinto

\footnotetext{
${ }^{40}$ Nombre oficial del Complejo Deportivo tras la reconstrucción de Santiago Calatrava. Información extraída de la página oficial, http://www.oaka.com.gr/?lang=en
} 
estaban rotas o arrancadas y los elementos de mental que componían el complejo en su mayoría, se mostraban enmohecidos. Diversos elementos arquitectónicos habían sido cubiertos con etiquetas o grafitis. Los estanques estaban vacíos, albergando pequeñas cantidades de agua sucia y, las fuentes, estaban secas. Las plazoletas o los caminos que comunican éstas presentaban restos de basuras, pudiéndose apreciar que las zonas de desechos no estaban habilitadas. El Muro de las Naciones, que fue construido con diversas piezas que le permitían movilidad para provocar un efecto ondulatorio, estaba estropeado e inmóvil.

Tras el primer día de observación y la tras la obtención de información y de documentos gráficos, era apreciable que los empleados del complejo limpiaban y ordenaban las zonas periféricas pertenecientes a las zonas deportivas aún activas. Las grandes zonas vacías, que fueron construidas para albergar a un gran número de visitantes, ahora daban la impresión de vacío y abandono. Estas zonas, sin habilitar para una práctica específica deportiva, quedaban disponibles a grupos de personas que, por su propia iniciativa, iban a correr, pasear, patinar, jugar con coches de control remoto y otras actividades.

El velódromo, en mejores condiciones que el resto de instalaciones deportivas observadas, mostraba algunos de sus cristales y puertas rotos y con pintadas, algunos cables colgaban del techo. Debido a que esta instalación era cubierta por su carácter específico en los Juegos, se había visto menos afectada como consecuencia de los cambios climáticos y atmosféricos, a pesar de su uso en ocasiones muy puntuales.

En cuanto al Centro Acuático Olímpico, éste ya estaba construido antes de la celebración de los Juegos, excepto la piscina utilizada para las competiciones de waterpolo, por lo que simplemente necesitó de una remodelación. Este complejo se componía de dos piscinas al aire libre y una cubierta. El vaso principal tenía un aforo de once mil espectadores, por lo que en un primer momento, se analizó la posibilidad de cerrar este espacio con una cubierta aunque finalmente no se llevó a cabo. ${ }^{41}$ En cuanto a las instalaciones deportivas relativas a este complejo acuático, se pudo observar que la piscina principal estaba en activo y en buen estado, dando servicio a clubes deportivos. Los locales donde se situaban los gimnasios y vestuarios, construidos debajo de las tribunas, tenían un buen mantenimiento, pero no era así el estado de las butacas en las tribunas. Las entradas habilitadas para el acceso a los asientos estaban llenos de restos de plásticos y basuras, algunas lámparas estaban estropeadas y las butacas sucias. La mayoría de butacas VIP se retiraron. Los suelos de las tribunas, excepto la zona VIP y la zona habilitada para

41 “Atenas 2004”- Informe Oficial, p. 257.

Citius, Altius, Fortius Volumen 9 ne 1 Mayo, 2016. ISHN. 2340-9886. http://dx.doi.org/10.15366/citius2016.9.1 
los medios de comunicación, fueron construidos de chapa, con lo que la humedad había hecho que el material se oxidara, constituyendo un elemento peligroso en la actualidad. Estos elementos pueden observarse en la Foto 1.

El vaso habilitado para saltos, que no fue utilizado durante los Juegos, sirvió durante aquellos para habilitar una tribuna adicional. La poca cantidad de agua que éste contenía tenía un aspecto sucio y verdoso (Foto 2). El vaso que albergó durante la celebración de los Juegos las competiciones de natación sincronizada podía observarse que era utilizado en la actualidad. La última instalación perteneciente al Centro Acuático que fue observada era una sala cubierta. Esta sala guardaba aún vallas de los Juegos Paralímpicos que se celebraron tiempo después que los Juegos Olímpicos de 2004. A pesar de ello, esta piscina tenía uso, algunos clubes la utilizaban y, durante la observación, se pudo comprobar el desarrollo de las clases. Otras salas, como las destinadas a la atención sanitaria, estaban descuidadas y en desuso. En los túneles y pasillos que unen estas instalaciones dentro del Centro Acuático, a pesar de no tener un mantenimiento óptimo, podían observarse ciertos cuidados.

El Estadio Olímpico, instalación principal del complejo O.A.K.A. y protagonista en los Juegos, es visible desde largas distancias y supone un icono para la ciudad. Este estadio fue construido a finales de los años setenta y originalmente era descubierto, encargo arquitectónico que llevó al frente Santiago Calatrava, que dispuso un techo transparente que cubría las tribunas y que se sostenía en dos arcos de acero gigantes. Las competiciones atléticas, la final de fútbol y las ceremonias de apertura y clausura, elemento característico en los Juegos, tuvieron lugar en este emplazamiento, que podía albergar a setenta y dos mil espectadores. ${ }^{42}$ Éste guardaba uno de los elementos más característicos de los Juegos en sus proximidades: la llama olímpica. En la actualidad entrenan en estas instalaciones diversos clubes de fútbol como el Panathinaikó y AEK Atenas Fútbol Club. Además, acoge otro tipo de actividades culturales y eventos musicales. El complejo O.A.K.A. fue diseñado desde el principio para ser el centro de operaciones de los Juegos. Se planteó que, tras los Juegos, sirviera como aliciente para la práctica de actividad física de la comunidad cercana, pero el deterioro de parte de sus instalaciones, sobre todo aquellas que la hicieron original y llamativa, no hace hoy en día atractiva su visita para la práctica deportiva.

42 “Atenas 2004”- Informe Oficial, p. 273.

Citius, Altius, Fortius Volumen 9 ne 1 Mayo, 2016. ISHN. 2340-9886.

http://dx.doi.org/10.15366/citius2016.9.1 
En la observación realizada de aquellas instalaciones se pudo apreciar cómo, a pesar de su funcionalidad actual, el estadio mostraba evidente falta en el mantenimiento de limpieza. El césped, a diferencia de otras zonas del Estadio, estaba bien cuidado. En la zona de salto, el foso de arena, contenía malas hierbas y las rejillas de drenaje estaban en mal estado. Las zonas que fueron habilitadas para la carrera de obstáculos mostraban en los fosos agua sucia. En el mismo espacio, se pudo comprobar cómo el cuidado de los emplazamientos destinados a fútbol tenían un mayor mantenimiento que la zona de atletismo. Esto se debe, principalmente a dos razones, a la obligatoriedad del buen mantenimiento debido a que dos clubes de fútbol entrenan allí y a la gran afición del pueblo griego por este deporte en detrimento de otros.

Un claro ejemplo de la falta de aprovechamiento del potencial de las instalaciones deportivas son los campos de voleibol playa o las zonas de juego de hockey hierba (Foto 3 y 4). La arena de los primeros y el césped de los segundos así como sus tribunas, contienen malas hierbas que no hacen viable ni atractiva la práctica deportiva en ellos.

Por el contrario, un ejemplo positivo es el Estadio Panathinaikó (Foto 5), el cual sirvió durante los Juegos para las competiciones de tiro con arco. En este estadio tuvieron lugar los primeros Juegos Olímpicos restaurados y, debido a su carácter histórico, antes del año 2004 se modernizó la cancha y la pista, se instaló el sistema de megafonía, el sistema de iluminación y el sistema contra incendios. ${ }^{43}$ Además, la meta del maratón tuvo lugar en este lugar. Antes y, en mayor medida, tras los Juegos del 2004, este estadio es una de las atracciones turísticas de Atenas. En la entrada se puede obtener un servicio de audioguía donde el visitante tiene acceso, en numerosos idiomas, a la historia del mismo y a sus elementos de construcción. En su parte final, atravesando un túnel debajo de las tribunas, se accede a una exposición sobre la historia del Estadio y de los Juegos, mostrando en una sala todas las antorchas y carteles de los Juegos Olímpicos modernos. Su valor histórico es inmenso, por lo que su mantenimiento es impecable.

Otra de las construcciones utilizadas fue el Zappeion, edificio situado en los Jardines Nacionales en el centro de Atenas. Esta construcción se usó durante los primeros Juegos modernos para las competiciones de esgrima, siendo desde 1999 la sede del Comité Organizador y durante los Juegos como uno de los centros de prensa. ${ }^{44}$ Este edificio tuvo uso antes y después de los Juegos como un centro de exposiciones y conferencias. Del mismo modo que el Estadio Panathinaikó, el Zappeion es una construcción antigua con funcionalidad en la actualidad.

43 "Atenas 2004" - Informe Oficial, p. 237.
44 “Atenas 2004" - Informe Oficial, p. 117.

Citius, Altius, Fortius Volumen 9 ne 1 Mayo, 2016. ISHN. 2340-9886. http://dx.doi.org/10.15366/citius2016.9.1 


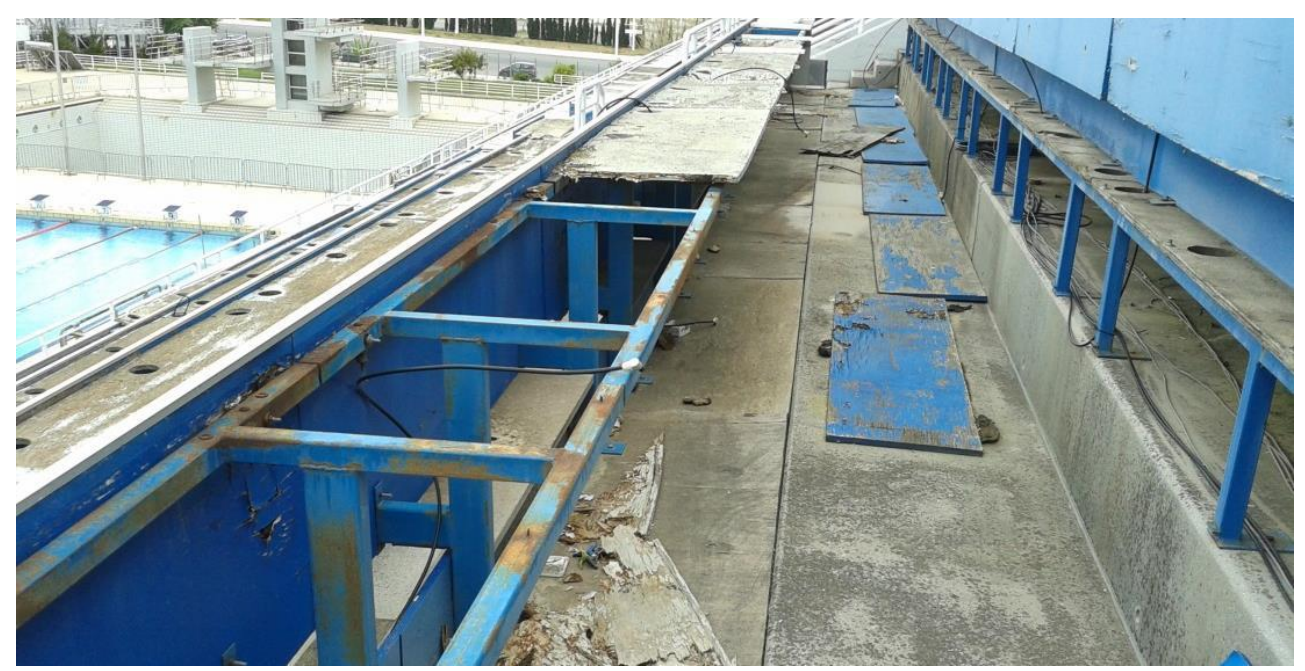

Foto 1. Tribunas del Centro Acuático Olímpico nueve años después de su construcción. Foto tomada por los autores en marzo del 2013.

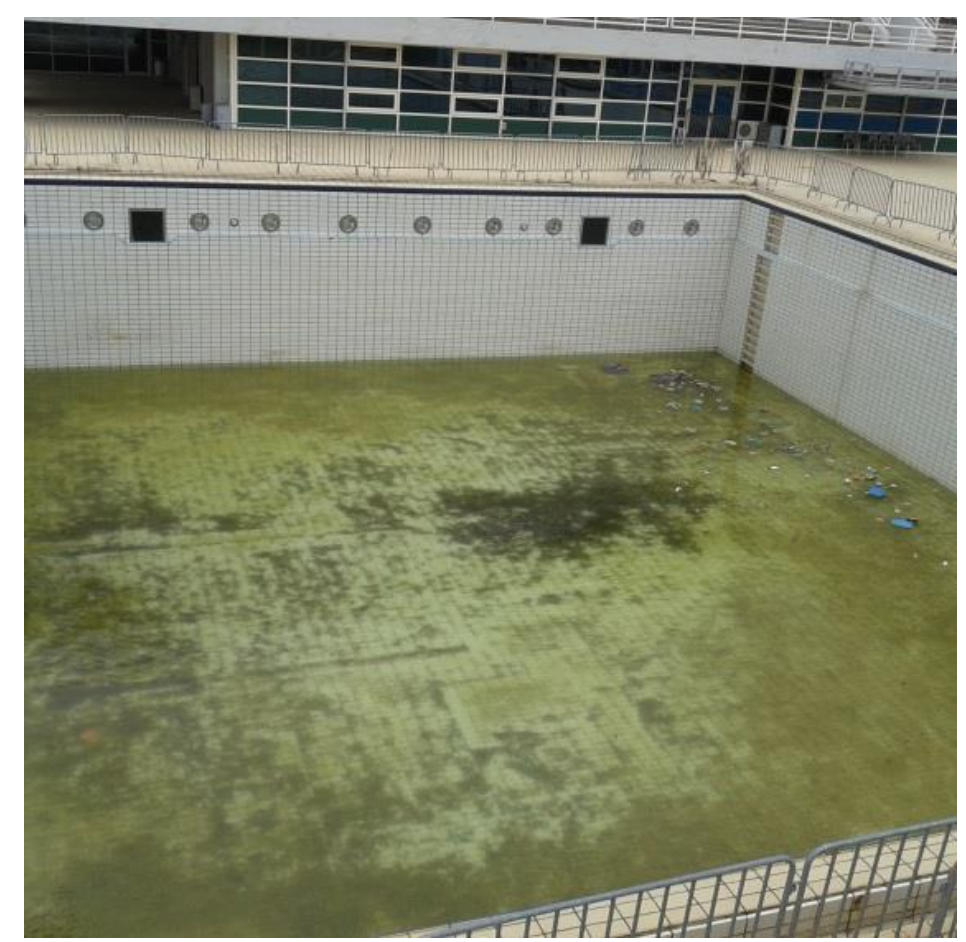

Foto 2. Vaso perteneciente al Centro Acuático Olímpico nueve años después de su construcción. Foto tomada por los autores en marzo del 2013.

Citius, Altius, Fortius Volumen 9 ne 1 Mayo, 2016. ISHN. 2340-9886.

http://dx.doi.org/10.15366/citius2016.9.1 
Otro lugar de gran importancia durante los Juegos de 2004 fue el estadio de Olimpia (Foto 6). Se decidió que en este lugar histórico y cultural tendría lugar la competición de lanzamiento de peso. Sin embargo, por el valor histórico particular y la protección arqueológica, no se colocaron ningunos elementos visuales (vallas, banderas, etc.), tribunas temporales, pantallas eléctricas o iluminación artificial. ${ }^{45}$ Los deportistas tuvieron que aceptar la carencia de elementos modernos y, de este modo, recrear cómo eran las competiciones en los Antiguos Festivales Griegos. Estas instalaciones continúan activas, siendo un gran atractivo turístico y académico. El servicio de guía es impecable y, debido a la cercanía y a su bagaje histórico, los invitados de todo el mundo que frecuentan la Academia Olímpica Internacional visitan asiduamente estas instalaciones. Además, con motivo de los Juegos de 2004, los museos de Olimpia se modernizaron, guardando su valor histórico con tecnologías de conservación modernas.

La Villa Olímpica fue uno de los proyectos claves en la preparación de los Juegos desde el comienzo. Se planificó que en el área de 165.000 metros cuadrados, en el barrio de Acharnes, a unos 15 kilómetros de Atenas, donde se construyeron viviendas de alta calidad. En el proyecto de estas instalaciones comenzaron a considerar la posibilidad de éstas en el futuro como barrio residencial. La OEK (Organismo público de vivienda para los trabajadores de Grecia) que se había interesado por la construcción de viviendas en esa región, financió este proyecto. Además de las viviendas, hubo que construir instalaciones complementarias como una clínica, un centro polideportivo, un parque de bomberos o centros de educación y de formación. Se retiró la línea de alta tensión subterránea y se trasladó, se construyeron redes de telecomunicaciones, gas y agua, así como la construcción de nuevas vías de unión con la carretera nacional.

En la actualidad, la Villa Olímpica es una zona amplia de viviendas pequeñas y de construcción típica ateniense. Desde el 2004 esta zona se está deteriorando gradualmente, el parque está poblado de hierbas y las instalaciones deportivas están descuidadas en su mantenimiento. Esta zona no tuvo como objetivo ser una zona deportiva, sino un área de descanso para los deportistas. Es por ello, que después de los Juegos debió ser integrada con el resto de la ciudad. Debido a que esta zona fue especialmente ideada para acoger a los deportistas de esta edición fue complejo integrar ésta a las necesidades de la población que más tarde la habitó. Su eficacia fue óptima en los Juegos, pero la integración de la misma a los intereses de los ciudadanos no fue tan fácil, ya que son los habitantes de una zona los que, a partir de sus necesidades, como la demanda de locales, servicios y zonas de recreo, la construyen.

\footnotetext{
45 “Atenas 2004" - Informe Oficial, p. 242.

46 “Atenas 2004" - Informe Oficial, p. 242.
} 


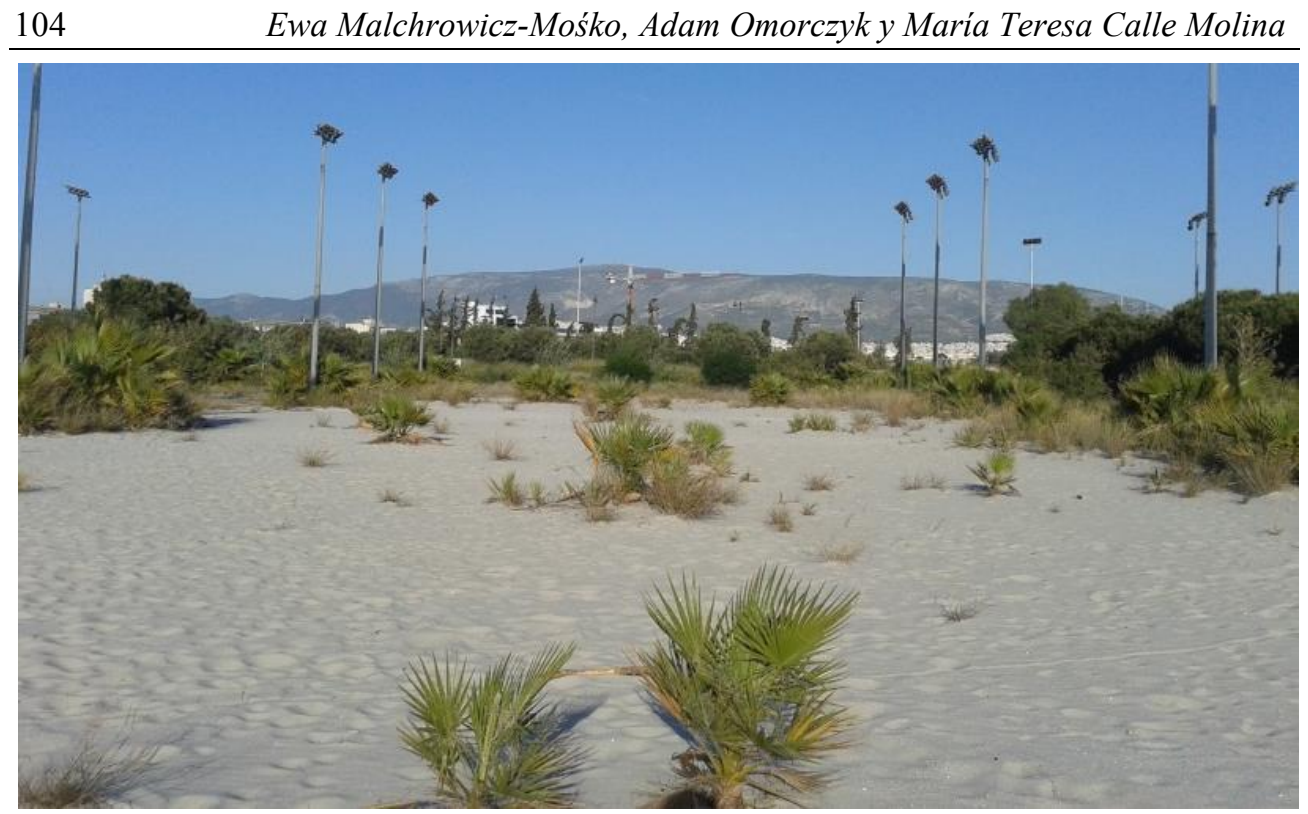

Foto 3. Campos de vóley playa nueve años después de su construcción. Foto tomada por los autores en marzo del 2013.

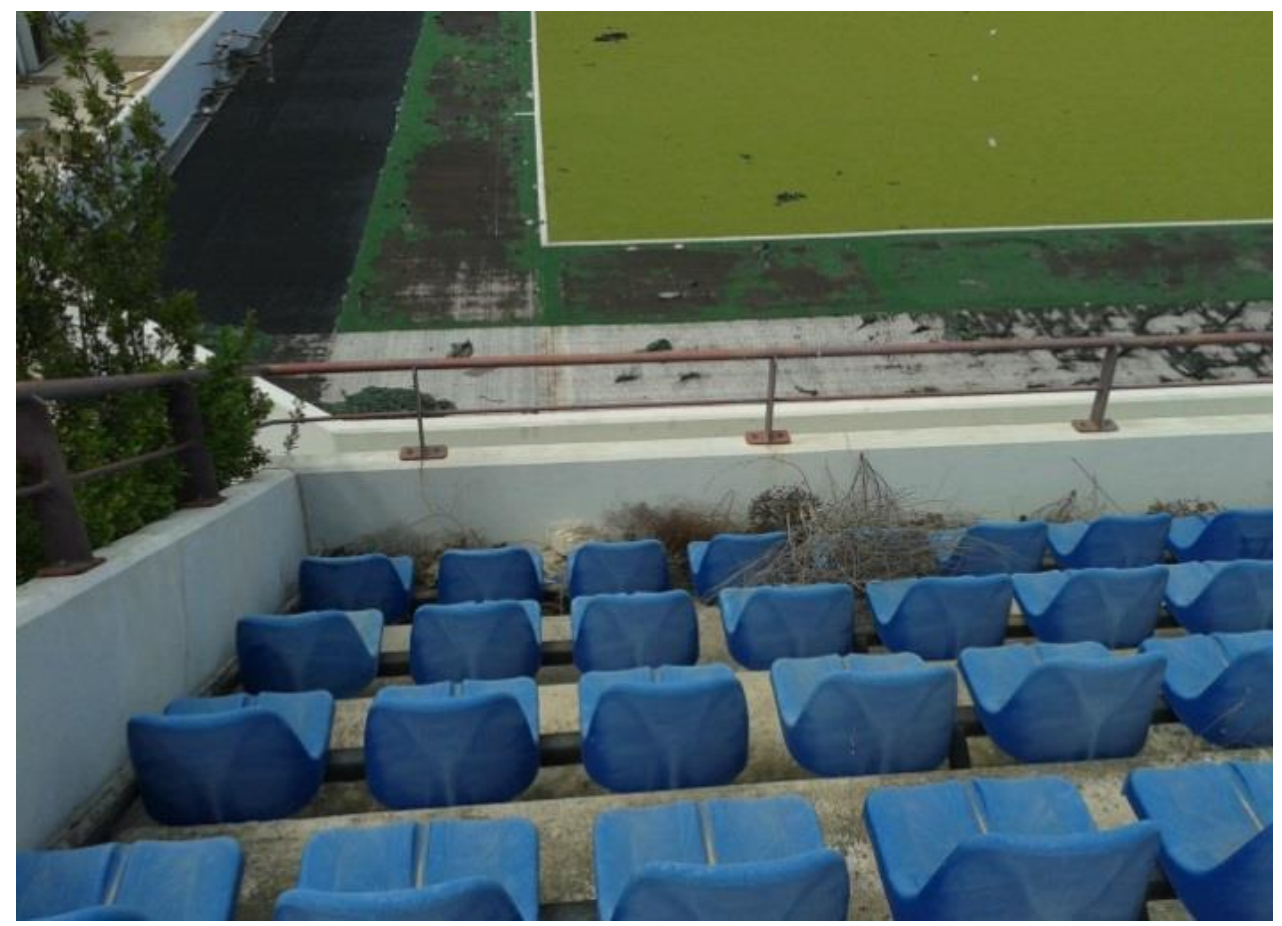

Foto 4. Tribunas pertenecientes al complejo de vóley playa nueve años después de su construcción. Foto tomada por los autores en marzo del 2013.

Citius, Altius, Fortius Volumen 9 ne 1 Mayo, 2016. ISHN. 2340-9886. http://dx.doi.org/10.15366/citius2016.9.1 


\section{Reflexiones}

Los Juegos Olímpicos son un evento deportivo de grandes dimensiones que se ha consagrado en la historia de la humanidad. El hecho de que su celebración sea cada edición en un país diferente supone un nivel organizativo muy importante económicamente hablando y muy amplio temporalmente. Las condiciones culturales, atmosféricas, políticas, económicas etc., de cada país son un factor que la organización de este evento debe tener presente. Los primeros Juegos que celebró Atenas en 1896 dieron la esperanza internacional de que era posible llevar a la práctica el ideal olímpico del barón Pierre de Coubertin. Con el paso del tiempo, la organización de los Juegos en diversos países ha aprovechado la celebración de los mismos como un medio de promocionar su país y mejorar su imagen a nivel mundial.

A pesar de que el ideal del barón sigue siendo palpable en los Juegos, la mediatización de los mismos puede verse contaminada en ciertas ocasiones por otros intereses bien distintos y ajenos al olimpismo. Por ello, no se debe olvidar que a pesar de que los Juegos son el escaparate internacional del olimpismo, las estructuras académicas del mismo siempre velan por la conservación de los Principios Fundamentales de este gran movimiento, recogidos en la Carta Olímpica.

Cada cuatro años, en un lugar diferente, se acoge un evento deportivo que transforma a la ciudad de acogida en un hogar internacional, donde confluyen diversas culturas, idiomas e ideales. La magnitud de estos eventos supone una preparación hercúlea y la trasformación de estructuras que, poco tienen que ver con el acto deportivo, deben estar preparadas para albergar a cantidades ingentes de visitantes y participantes. Ejemplo de este tipo de estructuras son las redes de carreteras, el transporte público, las zonas públicas (parques, plazas, jardines) etc., que generan una inversión económica muy elevada.

Existen diversos factores que determinan si el conjunto de infraestructuras derivan consecuencias positivas o negativas o, con mayor especificidad, si tienen una funcionalidad posterior a la celebración a los Juegos o no la tienen. La historia de los Juegos muestra que los cambios urbanos no siempre fueron bien pensados, que el futuro de las instalaciones deportivas dependió de la planificación previa de las mismas y que la funcionalidad de las instalaciones se conservó, con otros fines, en las etapas posteriores a los Juegos o bien no se llevó a cabo. Es por ello, que en algunas ocasiones se ha estudiado la posibilidad de construir instalaciones temporales que, con un coste menor, serían destruidas tras la celebración de los Juegos. Estas zonas no tienen ninguna funcionalidad después, pero son necesarias 
para la celebración de los Juegos, por ejemplo las tribunas, muy numerosas en todos los casos. Otra opción es la construcción de zonas que serían remodeladas con posterioridad para que su funcionalidad se adapte a las características de su realidad cotidiana.

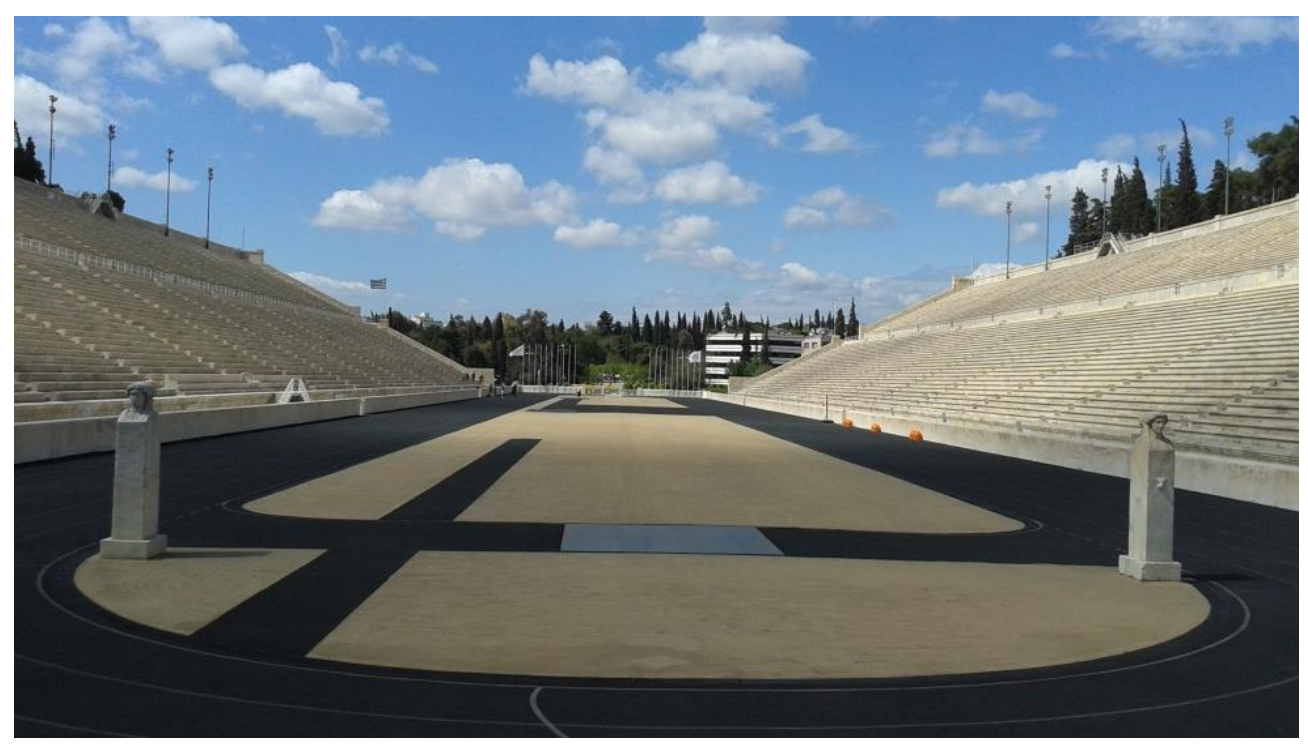

Foto 5. El Estadio Panathinaikó nueve años después de la terminación de los Juegos de Atenas 2004. Foto tomada por los autores en marzo del 2013.

En el caso de Atenas, tras nueve años de la celebración de los Juegos del 2004, sus instalaciones muestran deterioro y falta de mantenimiento. Una de las posibles causas podría ser la falta de planificación o anticipación de la organización del evento. El gasto económico destinado a la remodelación de las instalaciones deportivas ya existentes y para la construcción de las nuevas fue muy elevado $\mathrm{y}$, a pesar de ser imponderables para la celebración de los Juegos, no pueden presumir de ser funcionales en la actualidad. Las instalaciones deportivas de deportes como softbol, béisbol o vóley playa no son utilizadas debido a la poca popularización de éstos en la comunidad ateniense. La organización construyó tribunas temporales, pero no fue así con respecto a las instalaciones de estos deportes. El desuso, por tanto, de cualquier instalación provoca una falta de mantenimiento y un deterioro progresivo, que no sólo afecta a esa zona en concreto, sino a la imagen en general de todo el conjunto de instalaciones. 
El hecho de que las instalaciones estén vacías muestran un planteamiento $a$ priori de las mismas. Es bien conocido el hecho de que las instalaciones construidas para los Juegos de Atenas 2004 fueron afectadas por el síndrome del "elefante blanco". Este síndrome nace de una leyenda hindú, que explica como un maharajá solía regalar este animal a las personas por las que no tenía simpatía, ya que era único y bello en su especie, pero no era apto para trabajar, por consiguiente, su dueño se arruinaba en poco tiempo debido a los costes que generaba su mantenimiento. Esta leyenda ejemplifica un problema compartido por numerosas ciudades que han albergado eventos deportivos a escala mundial y que, tras ellos, se han visto obligados a reconvertir sus instalaciones a actividades que poco tenían que ver con fines deportivos y, en otros casos, al abandono y deterioro de las mismas.

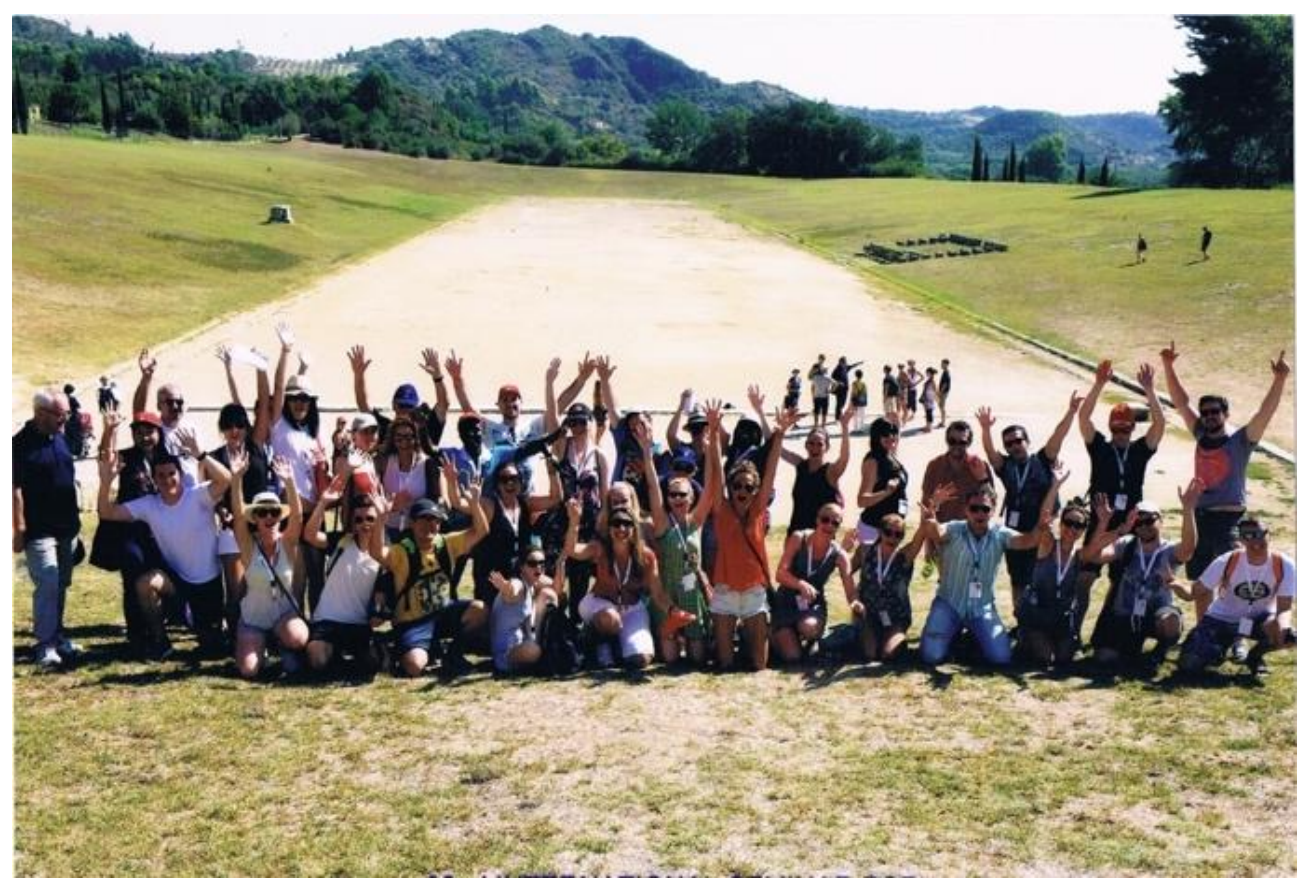

Foto 6. Participantes del $22^{\circ}$ Seminario Internacional en Estudios Olímpicos para Estudiantes de Postgrado de la Academia Olímpica Internacional en el Estadio de Olimpia. Foto tomada por los autores en septiembre del 2015. 


\section{BIBLIOGRAFÍA Y FUENTES}

\section{Fuentes documentales en páginas web}

- Informe Oficial de los Juegos Olímpicos de Atenas 2004, p. 117, 143, 157, 171, 257, 237, 242, 273.

- Comité Olímpico Internacional. Informe del 2013 sobre el legado olímpico:

www.olympic.org/documents/olympism_in_action/legacy/2013 booklet_1 egacy.pdf.

- Página oficial del estadio olímpico de Atenas Spiros Louis: http://www.oaka.com.gr/?lang=en

\section{Bibliografía}

- Bravo Ducal, J. (2008). Atenas 1896, Atenas 2004. Madrid: Real Federación Española de Atletismo y Comité Olímpico Español.

- Chappelet J.L. (2012). Mega sporting event legacies: a multifaceted concept, Papeles de Europa. pp. 76-86.

- Durántez Corral, C. (2004). Las olimpiadas modernas. Madrid: Pearson Educación.

- Durántez Corral, C. (2012). Los Juegos: las olimpiadas en la historia. Madrid: EDAF

- Girginov V., Social legacy of the Olympic Games, Learning Legacies, 2012.

- Hall C., Adventure, Sport and Health Tourism, [en:] B. Weiler, C. Hall (ed.), Special Interest Tourism, Bellhaven London 1992, p. 141-158.

- Miller D., Historia igrzysk olimpijskich i Międzynarodowego Komitetu Olimpijskiego. Od Aten do Londynu 1984-2012, Dom Wydawniczy REBIS, Poznań/Polska 2012, p. 362. 